\title{
Form Innovation and Musicality in Your Loneliness Is Knocking on My Window of Yunduo
}

\author{
Zhiyun Pan \\ Department of Chinese Linguistics and Literature \\ Yuan Ze University \\ Taoyuan, Taiwan
}

\begin{abstract}
Your loneliness is knocking on my window" in the first poetry anthology of Yunduo The Kingdom of Roses has stirred controversy. Her works are innovative in a unique and repetitive manner. The combination of punctuation marks and words shows the beauty of the changes in both images and music. And the innovative skills demonstrate the profound and endless emotions.
\end{abstract}

\section{Keywords-new poetry; concrete poetry}

\section{INTRODUCTION}

The first poems anthology of The Kingdom of Roses published by Yunduo in December 2012 was widely recognized and praised by the critics. Liu Zhengwei praised him for his achievements in the field of poetry creation ${ }^{1}$. Yindi believed that this is not an ordinary collection of poetry and he even asserted that at least ten years later, the future poetry field will be led by Yunduo. ${ }^{2}$ Her poetry has her own motives, and these factors cannot be ignored. Bai Ling is evaluated in the Preface to The Kingdom of Roses. Bai Ling made the comment in the preface to The Kingdom of Rose that:

At the end of youth, before going to middle age, she takes a breath and finishes the work of a young age--for example, after the completion of childbirth task, when suddenly there is something to say and must say, a dream that has gone away has to be caught up. She picks up her pen again and stands on the stage of her own construction to realize the dream of her youth or complete the dream. ${ }^{3}$

Yunduo is not only a poetess who has experienced years of training, but dreamed again after completing the "task" in life, but also she is a scholar with rich aesthetic and poetic research and review experience.

She studied the odes theory and aesthetics of the Six Dynasties with her original name, Li Cuiying.She published the Study of Fu Theory in the Six Dynasties in 1998, and

Liu Zhengwei, "The Sound Image of Rain in the Poems of Yunduo" Taiwan Poetry No. 17 (Taipei: Showwe, 2013), p. 139.

Yindi, "A Poet of Light" Diary of Yindi (Taiwan: Elitebooks press, 2012), p. 443.

Bailing, "Wings and Freedom--Preface of Yunduo's Anthology of The Kingdom of Rose"The Kingdom of Rose (Taipei: Niang Press, 2012), p. 14. published "the Theory of Creation and Aesthetics of $\mathrm{Fu}$ Theory in the Six Dynasties" in January 2002.Then she turned to the research of new poetry and published "the Palmprint of the New Poetry" in 2006 to discuss the skills and contents of the poem itself in the most poetic way ${ }^{4}$. In 2007, she published "the Voice of Snow- the Theory of New Poetry in Taiwan", discussing the problems of poets and works, works and creative techniques. Before the creation of "The Kingdom of Roses", she has been a mature aesthetic theorist and a Taiwan new poetry theorist and commentator.

"Your Loneliness is Knocking on My Window." was the most highly praised poem in The Kingdom of Roses. Liu Zhengwei commented that it was the poem that was the most deliberately managed in the form among the entire poetry. The whole poem is divided into three paragraphs and ten lines. In addition that there are quite a lot of textual differences between the two lines in the first and last paragraph respectively :"It is raining!" and "Loneliness...",from the second to ninth lines, there are mostly the replacement of some phrases, such as "outside, yours, lonely, knocking on my window "and "yours, lonely, outside, tapping my window", etc. The poet wants to create an atmosphere that stays awake for a long night and the rain slams through the window all night long to reflect a sense of loneliness in my heart. ${ }^{5}$

In this way, the author will explore aesthetics creativity of "You Knocking on My Window Using Loneliness" from two perspectives.

The first point is to demonstrate the creativeness of repeated aesthetics in this poem. In the "repeated" poetic study, some scholars have researched its significance. One of the more representative views is Levi-Strauss's analysis of the "Structural Analysis of Myths": "Why does myth and more general oral literature always repeat the same sequence arrangement, once, twice or four times? If our premise is accepted, then the answer is obvious: the role of repetition

Cuiying Li, "Give You A Fishing Rod for A New Poem."The Close Reading on the Palm Prints of New Poetry(Taipei: Wanjuanlou Publishing House, 2006), p. 2.

5 Liu Zhengwei,op.cit., pp. 139-140. 
itself is to make the structure of mythology visible." 6In his view, repetition can make the value of certain elements in literature stand out. Yunduo increases the "repetition" in modern poetry to the height of aesthetics and he thinks "repetition" is a basis for beauty. ${ }^{7}$

However, this is not a monotonous repetition. Yunduo combines the repetition and sense of rhythm in Taiwanese new poetry with the intention of creating a special effect of rhythm by designing and arranging sounds, order, or arrangement to express emotion or mood. ${ }^{8}$ Jiang Yizheng focuses new poetry on the field of concrete poetry and notes that the musical part in modern image poetry. In addition to the visual function of image poetry, she summarizes the importance and influence of musicality in image poetry. ${ }^{9} \mathrm{Liu}$ Zhengwei also notices the sound image of poetry of Yunduo. ${ }^{10}$ The author will explore some of creativity of the aesthetics of the visual and auditory images in "Your Loneliness is Knocking on My Window." to deal with the novelty of this poem by using the above two perspectives.

\section{THE BEAUTY OF BIG NUMBER - THE UNIQUENESS OF REPETITION}

"Repetition creates a structure for what we read. The repetition of scenes, words, concepts, and images can create temporal and spatial rhythms that form the basis for consolidating our cognition: we repeat the beat again and again (and treat them as a feeling of pulsation) to understand the meaning of the text." ${ }^{11}$ This poem uses "repeat" techniques in the arrangement of words. From the second sentence to the antepenultimate sentence, in the text, Yunduo only uses the words "You are knocking on my window curtain outside with loneliness" to form a repetition of words. In the connection of the arrangements and aesthetics of the same words and sentences, Xu Zhimo thinks that "the big number seems to exist according to a natural law and there will be a special arrangement, a special rhythm, a special style to excite our aesthetic instinct and stimulate our aesthetic emotion. ${ }^{12 "}$ This coincides with Yun duo's research on "Repetition" aesthetics in new poetry. In her book "the Voice of Snow - the Theory of New Poetry in Taiwan", she says:

"From an aesthetic point of view, the big number is a kind of beauty. Using more than one times of repetition to create a strong and powerful effect is also an aesthetic

$6 \quad$ Claude Levi-Strauss, "Studies of Structuralistic

Mythology"Wang Fengzhen, The selection of the latest Western Literary

Theory (Guilin: Lijiang Publishing House, 1991) ,p. 121.

Li Cuiying, "Rhetorical Skills Based on Repetition-- on the changes of the rhythm of the new poetry" The Sound of Snow--the Theory of New Poetry in Taiwan (Taipei: Wanjuanlou Publishing House, 2007),p. 269.

$8 \quad$ Ibid., p. 268.

$9 \quad$ Jiang Yizheng, Musicality in Modern Concrete Poem (Taipei:

Showwe Publishing House, 2012), p. 5.

10 Liu Zhengwei,op.cit. , pp. 139-140.

11 Krystyna Mazur,Poetry and Reputition:Walt Whitman,Wallace Stevens,John Ashbery(New York/London:Routledge,2005),p.4.

12 Hsu Chih-mo, "Diary", Huang Qingxuan, Rhetorics (Taipei: San Min Book Publishing House, 1975), p. 412. presentation, and repeated stimulation produces a stronger psychological connection."

Yun duo also makes use of this concept in "Your loneliness is knocking on my window". The whole poem is divided into three sections and ten lines. In addition that there is a relatively large narrative difference between the two lines of the first and last, "It's raining!" and "Loneliness...", from the second to the ninth lines, there are the split and replacements of "Your loneliness knocks outside on my window."

In the creation of concrete poems, it is not a rare phenomenon to pile up images with the repetition of words and phrases. However, the minimum unit of repetition of image poetry is generally short, which impresses readers with shortness and intense. "Your loneliness is knocking on my window" has a significant increase in the number of duplicated words, reaching thirteen words, and further elongating it with punctuation marks. In addition to the repetitive emotional stimulation, the rhythm of the poem is slowed down, and the length of the smallest unit itself has a slow and endless effect on the emotional expression of this poem.

If repetition is more focused on strengthening the depth of current emotion, sentence stretching is more inclined to express endless emotion in the dimension of time. The poet tend to create a sleepless night and the noise of the raindrops, reflecting the great loneliness of my heart. ${ }^{14} \mathrm{As} \mathrm{Li}$ Kuiyun wrote in the study of the imagery of rain:

The fall of rain is like a person's tears. As rain is the tears of the sky, when the heart is directly transferred to the outside world, the rain will become a symbol of sadness. ${ }^{15}$

The fall of rain is also the fall of the poet's tears. The poet's tears strengthened the language through repeated repetitions. Together with the lengthening of the words, the poet's inner heart was marked by a huge and continuous feeling of sadness and loneliness. The "you" in the poem is actually another lonely self in the poet's heart ${ }^{16}$. The "outside" "you" seems to be separated from me, but it reminds me of "loneliness" with the rain and continues to "hit" "outside" not far. Throughout the ages, "loneliness" has always been particularly sensitive to the sharp nerves of the poet $^{17}$, and this poem is also intoxicated with intense and continuous loneliness.

The author uses the repetition of the sentence and lengthened the smallest unit of the repetition itself. The former represents the intense and deep emotion of the present, and the latter reflects the prolongation of the

3 Li Cuiying, op.cit., p. 268.

14 Liu Zhengwei, op.cit., pp.139-140.

15 Li Kuiyun, "Waiting You in the Rain-- on the 'Rain' Image of Modern Female Poetry"Between Structure and Symbol: on the Images of Modern Female Poetry in Taiwan(Taipei: Lernbook Publishing House, 2008), p. 40.

16 Liu Zhengwei, op.cit., p. 140

17 Xiao Xiao, “ The Feeling of Loneliness in Taiwan's Poetry", Modern Aesthetics of New Poetry(Taipei: Elitebooks Publishing House, 2007), p.139 
emotion of the poem in time. The combination of the two forms the uniqueness of the poem in emotional expression.

\section{THE BEAUTY OF CHANGE - THE COMBINATION OF AUDIO-VISUAL IMAGERY}

Imagery as a basic category of poetry aesthetics, the poet's aesthetic feelings and the reality of the scene realize harmony and unity in the language, constituting a unique aesthetic of poetry. As an image poem, ${ }^{18, ' Y o u ~ K n o c k ~ o n ~}$ My Window with Loneliness" also has a certain degree of innovation in the visual creation

From a visual point of view, the poetic shape of this poem is similar to a rectangular window. The window is viewed as simultaneously having two contradictory attributes of "connects and disconnects". 19

The windows are both connected and separated. It is an obstacle standing between the viewer and the viewed one,however,It strictly prohibits the contact of them.

Because of its existence at the same time, the refinement of the viewing behavior and the analysis of the external objectivity can be preserved and affirmed. Although the window is an obstacle, it also guarantees the conduct of gaze and safely isolates interference that may come from outsiders. $^{20}$

The window itself will give people the impression of imprisonment and limitation. The "loneliness" outside the window is isolated from me in the window, but it is also possible to see the existence outside the window, and the bed is easy to agglutinate people's spirit and make them focus on the world outside the window followed by that be influenced by the things outside the window. Through the gaze of "me" on the window scene, the window becomes a medium. Just like the last two sentences in the poem, the loneliness outside the window finally strikes the "me" in the window and rings my loneliness. In addition, the window is not entirely an objectively-existing landscape, but it is also a projection of the inner thoughts and emotion of "me" under outsider objects as well as a projection result of the subjective impression of "me" to the objective outsides.

From the details, the verses of this poem are divided by a large number of punctuation marks and rearrange the poetry lines to create that "I" also like a scene in the rain that shown by the window and like intermittent raindrops ${ }^{21}$. The fall of rain is like the falling tears of a man. As the rain symbolizes the tears of the sky, the direct transferring of people's heart to

18 Li Yuanluo, "Fireworks in the Poetry_ on the Beauty of Poetic Images", "Poetry Aesthetics" (Taipei: Dongda Publishing House, 1990), p.143.

19 Cai Xiuzhi, "Reading on the Symbol of the City Image", Doctoral Thesis, Anglo American Institute of National Taiwan University (Taipei: 1997) p.146.

$20 \quad$ Ibid ,p.146.

21 Li Kuiyun, "Waiting You in the Rain-- on the "Rain" Image of Modern Female Poetry", "Between Structure and Symbol: on the Images of Modern Female Poetry in Taiwan" (Taipei: Lernbook Publishing House, 2008), p.40. the outside world makes the rain a symbol of grief. ${ }^{22}$ The fall of the rain can be interpreted into the dripping of tears, which is tapping the lonely self. The last line is just like the endless rain.

This poem is not only a concrete poem, but also a sound poem for the entire surface of the rain that rang through the windows, which appears in the reader's mind. ${ }^{23}$

From an auditory point of view, when interpreting the application of punctuation and the meaning behind punctuation in "you are knocking at my window using loneliness", it is advised that the study of punctuation application of Yunduo to "the Rain in the Morning" created by Chen Dawei. With regard to the use of punctuation marks in "the Rain in the Morning", Yun duo thinks that the meaning it illustrates is like this:

In the last line of each paragraph, there is a punctuation mark. From the first paragraph, it is "-", which represents the length of affection; the second paragraph is ";", and the use of ";" means that the semantics are unfinished and can be supplemented; the third paragraph is "," indicating that the plot continues; the fourth paragraph uses ";", which means that the next paragraph is different and the plot changes as well as the tone changes; the fifth paragraph uses "," to signify a temporary break in tone, and the next paragraph continues with the progress of the plot; the sixth paragraph is "..." with infinitely extended meaning. ${ }^{24}$

Just like Chen Dawei, Yunduo does not use periods during the design of punctuation marks. Instead, she mostly uses symbols to temporize or prolong the meaning of literary tactics. For example, Chen wants to imply that he hopes of lingering love by the design of punctuation and ${ }^{25}$ the author also wants to hint that the mood is endless. In the same way, the "," in the Yunduo's poems can be interpreted as meaning that the semantics are not yet finished. At the same time, "..." is also intended to express the meaning of lingering. Punctuation marks break apart the sentence, making the original coherence of the poem interrupted. When reading aloud, it will have a sense of stagnation, making the work emotional depth besides a long melancholy. Meanwhile, as mentioned in the previous article, in the respect of the hearing, the pause caused by punctuation can be explained that the rain drops constantly to try to interrupt the sadness and loneliness, but the melancholy of the protagonist is still unable to be discharged.

Yunduo takes punctuation as a symbol of rain, which bears the dual aesthetic function of vision and hearing. It shows the originality of the form while expresses both the length of time and the heavy affection in the transmission of emotion.

\footnotetext{
22 Ibid, p.40.

23 Liu Zhengwei, op.cit., pp.139-140.

$24 \quad$ Li Cuiying, "Adolescents Are Always Brimming with Romantic Feelings", "The Close Reading on the Palm Prints of New Poetry" (Taipei: Wanjuanlou Publishing House, 2006), p. 253.

25 Ibid., p.253.
} 


\section{CONCLUSION}

Through the image poem "Your loneliness is knocking on my window", Yunduo skillfully melts the writing skills into a furnace. Through the clever combination of words and sentences, it is innovative to convey the long and sincere feelings with the changes and non-changes in the repetition. She raised the writing style of new poetry to the height of aesthetics, and provided more possibilities for the creation of new poetry.

First and foremost, she created a new form of repetition, and creatively lengthens the smallest unit of repetition, making the emotion of poetry rich in current concentration and long in terms of time. The expression style of new poetry, especially the image poetry is expanded to a new way of thinking. As for the idea and application of its repeated aesthetics, it is necessary to look forward to the in-depth discussion and research of subsequent scholars.

In addition to the performance of rhythm, the visual and auditory sense of the same symbol overlaps the different sensory combinations of the imagery. The complexity of the dimensions of its representation has its originality in the field of Taiwanese new poetry, which can provide new ideas for the later creator.

With the creativity in form and the innovative use of puntuation marks, "Your loneliness is knocking on my window" enriches the formative techniques of modern Taiwanese poetry, and it has accomplished further breakthroughs in the creation and research of Taiwanese new poetry.

\section{REFERENCES}

[1] Bailing, "Wings and Freedom—prologue to The kingdom of Rose", "The Kingdom of Rose" (Taipei: Niang Publishing House, 2012).

[2] Cai Xiuzhi, "Reading on the Symbol of the City Image", Doctoral Thesis, Anglo American Institute of National Taiwan University (Taipei: 1997).

[3] Claude Levi-Strauss, "Studies of Structuralistic Mythology", Wang Fengzhen, "The selection of the latest Western Literary Theory" (Guilin: Lijiang Publishing House, 1991).

[4] Huang Qingxuan, Rhetorics (Taipei: San Min Book Publishing House, 1975).

[5] Jiang Yizheng, Musicality in Modern Image Poem(Taipei: Showwe Publishing House, 2012), p.5.

[6] Krystyna Mazur,Poetry and Reputition:Walt Whitman,Wallace Stevens,John Ashbery (New York/London:Routledge,2005),p.4.

[7] Li Cuiying, "The Close Reading on the Palm Prints of New Poetry" (Taipei: Wanjuanlou Publishing House, 2006).

[8] Li Cuiying, "The Sound of Snow_ the Theory of New Poetry in Taiwan" (Taipei: Wanjuanlou Publishing House, 2007).

[9] Li Cuiying,The Kingdom of Roses,(Taipei:Niang Press,2012).

[10] Li Kuiyun, "Between Structure and Symbol: on the Images of Modern Female Poetry in Taiwan" (Taipei: Lernbook Publishing House, 2008).

[11] Li Yuanluo, "Fireworks in the Poetry — on the Beauty of Poetic Images", "Poetry Aesthetics" (Taipei: Dongda Publishing House, 1990).

[12] Liu Zhengwei, "The Image of the Sound of Rain in Yunduo's Poetry", "Taiwan Poetry No.17" (2013), p.139-140.
[13] Xiao Xiao, "The Feeling of Loneliness in Taiwan's Poetry", "Modern Aesthetics of New Poetry" (Taipei: Elitebooks Publishing House, 2007).

[14] Yindi, "A Poet of Light", "Diary of Yindi" (Taiwan: Lernbook Publishing House, 2012). 